\title{
Delineating policing towards a social and health profession
}

\author{
Uzma Williams* and Daniel J. Jones*
}

\begin{abstract}
This article suggests potential reforms required to address shortcomings of the policing profession in response to contemporary challenges. Police reforms that de-emphasize enforcement and promote policing as a helping profession are discussed. This stance is presented because police calls for service commonly involve complex human behaviour that includes mental health factors (including addictions) and diversity. Police officers require extensive training and education on mental health and diversity, which should include regular specialized training advancements in professionalism, interpersonal skills, and behavioural (non-verbal and verbal) response. All police officers have to deal with mental health and diversity, and, as such, an appropriate helping model (that adopts certain skills from health and social professions) should be incorporated into law enforcement practices and training. The Compass Police Response (CPR) Model is presented for consideration in police reform as well as a revised representation of the Police Use of Force Framework. The authors posit that policing should include increased collaboration with health and social professions. The support of other community disciplines and health systems is necessary to adequately address reforms required in the policing profession.
\end{abstract}

Key Words: Interprofessional and multi-disciplinary collaboration; diversity; mental health; police; Compass Police Response (CPR) Model; Police Use of Force Framework.

On May 25, 2020, 46-year-old George Floyd was arrested and died at the hands of the arresting officer in Minneapolis, Minnesota, in the United States of America. The police officer was eventually charged with murder in the case (State of Minnesota v. Derek Chauvin, 2020). Instant outrage at the police action that caused the death of Mr. Floyd resulted in riots and calls for police abolition - or at least massive police reform. Mishandling wellness calls across Canada has also contributed to loss of community support. Community hostility towards police has increased in response to incidents of police brutality, legitimacy, competency, and accountability.

Communities are advocating to defund, de-task, and abolish the police. However, this begs the question: How will things be different from before if we de-task and defund the police? Police will still be required to respond to calls that may, unknowingly to the officer or callers, require competency to address mental health wellness and diversity. In this paper, mental health competency refers to an officer's awareness of mental health disorders and crisis symptoms and the corresponding ability to respond appropriately using interpersonal and behavioural skills. Diversity competency refers to fair treatment of vulnerable populations based on ethnicity and on sexual and gender diversity. We make the case that mental health will never be detangled from policing and that policing is not only law enforcement. In order to respond appropriately to issues involving mental health and diversity, a new model of police response is required that rectifies current shortcomings in police education and culture and reimagines policing as a helping profession.

\section{POLICING IS A HEALTH PROFESSION INVOLVING HUMAN SOCIAL COMPLEXITIES}

Police are experiencing turmoil due to the increasing use of video cameras and social media that is exposing police incompetency and abuse of powers (Ariel et al., 2015). It is possible that police brutality is actually decreasing, because officers are now under a microscope (Ariel et al., 2015). The concept of police legitimacy, where the community sees the police as a legitimate power holder, is often discussed. The concept of self-legitimacy is less commonly discussed and refers to whether police officers see themselves as legitimate (Nix \& Wolfe, 2017; Tankebe, 2014). Negative media coverage impacts officers' sense of self-legitimacy, and reduction of

Correspondence to: Uzma Williams, 9-411A Robbins Health Learning Centre, 10910104 Ave NW, Edmonton, AB T5J 4S2
E-mail: uzma.williams@macewan.ca
To cite: Williams, U., \& Jones, D. J. (2020). Delineating policing towards a social and health profession. Journal of Community Safety and Well-Being, 5(4), 156-163.
https://doi.org/10.35502/icswb.171
@ Author(s) 2020. Open Access. This work is distributed under the Creative Commons BY-NC-ND license. For commercial re-use, please contact sales@sgpublishing.ca.

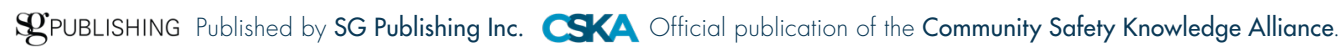


officer self-legitimacy can result in higher rates of police mental health crisis (Nix \& Wolfe 2017).

When we examine flawed responses to wellness checks or calls involving a visible minoritized individual, it is likely that police, like the general public, are fearful of mental health symptoms and persons visually different from themselves (Mimiaga et al., 2010; Sweeney et al., 2015). Some investigators suggest that inappropriate police response may result from a lack of formal education, knowledge, or familiarity (Laurance, 2003; Smith \& Robinson, 2019). We focus on familiarity in the next few sections.

In psychology, an acute stress response is experienced when a person feels threatened by too many strong emotions and perceives danger. This acute stress response is activated by the sympathetic nervous system consisting of flight (fleeing the environment), fight (confronting the threat), or freeze (Donahue, 2020; Webster et al., 2016). The acute stress response of fight is more likely to initiate among police officers because their training involves being able to respond to perceived threats (whereas freeze or flight are the least trained responses in policing). So when police perceive people acting bizarrely due to mental health symptoms or as physically different from themselves, one possible explanation for the use of excessive force is that the officer is reacting out of fear and responds extremely due to the trained fight response. This response of fear may be activated because officers' knowledge of and familiarity with mental health, in some cases, is no different than a lay person's whose understanding of mental health is based on news outlets or popular media (e.g., true crime, movies), which falsely depict persons with mental health as dangerous and homicidal. Many officers lack formal knowledge in the area of mental health disorders (as well as diversity). Once the officer is exposed to immersive mental health training, they can shift from sympathetic arousal of fight to social engagement, which is optimal arousal with a range of emotions where the person feels safe (Porges, 2010).

While police agencies employ special response teams that consist of police and mental health professionals, all officers should be trained in mental health because police are the first point of contact for many individuals critically requiring mental health services. The BC Division of the Canadian Mental Health Association (2005) found that police were the first point of contact for over $30 \%$ of individuals with serious mental health concerns.

Typical police calls often have an element of mental health concerns, and if the caller doesn't know about mental health or cannot identify mental health as a concern during the situation, then the special mental health police team may not be deployed to the call. For instance, odd, reckless behaviour, such as a person throwing objects onto cars in traffic, may be perceived as requiring law enforcement. On the surface, there is a disruption and a disregard for safety, which is a law enforcement issue. However, on a deeper level, an officer lacking knowledge about mental health would not have the skills to effectively deal with this situation. The mental health component would be ignored rather than addressed, such as through referral to appropriate services for a comprehensive and preventive response. This notion of mental health competency extends to police culture, where people are called "subjects" rather than "persons," enabling a mental reference of dehumanization.
Community-based policing models must encompass competency and professionalism in areas similar to what is required of the health and social professions (social work, psychology, medical practices, etc.) when dealing with mental health and diversity. When policing agencies are trying to lead a community-based response, it is necessary to view adequate response through a helping profession lens. Policing must become more interdisciplinary and involve and collaborate with health and social professionals rather than working in its own silo. This can be accomplished by enhancing the key components of professionalism, interpersonal skills, and appropriate behavioural and nonverbal/verbal response, which are discussed later in the Compass Police Response model.

A psychology-based response to many questions related to human behaviour is "it depends." Research pertaining to human behaviour presents much lower research scores (such as lower correlations at the most basic level) than research in science-, health-, and police-based fields. This is because research in the latter fields usually explores direct measures such as speed, hand strength, levels of chemical/substance contamination, autopsy findings, for instance, which are measured directly, with minimal margins of error. On the other hand, understanding human behaviours, in the field of psychology or sociology, for instance, involves abstract notions known as constructs, such as personality, intelligence, mental health, and diversity. By merely looking at someone you cannot determine their intelligence or mental health functioning, because there is much variation in and many contributors to these constructs. One presentation of post-traumatic stress disorder, with consideration given to age, incident type (e.g., sexual assault versus witnessing a murder), and severity, may present completely differently from someone else's despite the same factors of age, incident, and severity. The symptoms a person experiences depend on a multitude of factors that include the person's resiliency, family mental health conditions, biological disposition, etc. Human behaviour is intricate and complex. There are layers to unfold, and the police are in a position where they need to understand and respond to complex human behaviour-they work with individuals and their health, situating policing as a health and social profession.

Of particular interest are police-related custody deaths. A plethora of research indicates that up to $40 \%$ of police custody deaths are due to natural causes such as cardiac arrest (Wobeser et al., 2002) and mental health issues such as excited delirium resulting from substance use and physical constraint (Hall et al., 2015; Ross, 1998; Vaughan et al., 2017). Because a multitude of factors exist in the cause of death (Hall et al., 2015; Lindon \& Roe, 2017), the use of particular safe postures which do not compromise breathing and other physiological functions is recommended (Hall et al., 2015), as well as seeking medical advice if the person appears to be in medical distress (Ross, 1998). Training from a medical perspective is therefore required to deter police-related custody deaths.

Some people-including some police officers-may hold the position that policing should focus only on law enforcement. However, this route of action would be no different than the current state. A single focus on law enforcement in policing is impossible as policing involves people with complex behaviours (i.e., a range of mental health functioning and 
diverse visible backgrounds). Furthermore, the persons police encounter typically have lower-than-average mental health functioning or include a higher representation of minoritized groups (Goldberg et al., 2019; Thompson \& Kahn, 2016), once again positioning policing as a profession within the social and health branches.

A community-based approach and adopting the values of a helping profession within policing organizations will attract recruits who believe in and follow the tenets of a person-centred approach when helping individuals rather than emphasizing traditional law enforcement. Tables I and II describe the skills and values that contribute to making policing more person-centred-see Police Response to

TABLE I Values of a person-centred profession (Egan, 2013)

Respect and Dignity
Care
Trust
Genuineness
Empathy
Patience, Reasonable Flexibility, and Dependability
Non-Judgement
Proper Attitude, Social Modelling, and Avoiding Hostility
Confidentiality and Privacy

TABLE II Social skills of high-performing police officers

Speaking skills: Being able to use words and elements of language to instruct, inspire, and open dialogue while maintaining respectful eye contact.

Active listening and awareness in a situation: Attending, observing, and listening needed to develop an understanding of individuals and their world as well as avoiding distractions and being attuned to the situation through maintaining eye contact.

Extroverted, charismatic personality: A likeable sociable trait that also involves being open to diversity and being responsive to the needs of others.

Maturity and credible professional conduct: All professions have their own code of ethics and their members commit to adhering to that code upon assuming their role. The credibility of their profession relies on the honest, discrete, and everyday commitment to this code of ethics.

Practical reasoning skills: Accurate diagnosis of a problem by gathering information and taking the time to deliberate before acting.

Self-presentation: Appearing self-assured, genuinely confident (both in posture and voice), genuine, and self-controlled.

Good judgement: Ability to make immediate, informed decisions.

Self-awareness: Ability to reflect and learn from experiences as well as willingness to grow.

Effective dialogue: Techniques learned from counselling psychology such as validation, ratio of open to closed ended questions, summarizing, clarification.
Mental Health in Canada (Williams, Jones, \& Reddon, 2019) for a full description.

\section{OUR PROPOSITION: COMPASS POLICE RESPONSE (CPR) MODEL}

The Compass Police Response (CPR) model was created by the authors as one option to guide police officers who are seeking to improve their skills when dealing with individuals during police calls. In summer 2020, the authors received countless media calls to comment on the concerning nature and number of wellness calls where excessive force was used by police across the country. The authors were asked for a more appropriate model than what was currently being practiced when police respond to wellness and diversity calls. The CPR model originated from shortcomings of the Police Use of Force Framework. The CPR model (Figure 1) combines components of helping professions and law enforcement for an effective response to police calls, making it more appropriate when responding to wellness and diversity calls than the traditional and outdated Use of Force Framework. The CPR model is analogous to using a map while driving. The prerequisite to using the map is that the officer have an education in and understanding of mental health, which is crucial and necessary for all police officers-merely by working with people, policing requires social understanding and compassion. The appropriate response always moves from West to East and the disposition is from North to South.

The officer begins on the far West route when responding to police calls. The officer should always default to the West area, and should only venture into the East area as required. Weapons are based outside the map as they are a last resort, when there is an imminent danger posed to the officers or others in the immediate area, there are no choices, and weapons are deemed absolutely necessary.

When officers are deciding on a disposition, they need to "drive" North and South and stop where it's most appropriate. The disposition can range from no arrest to connecting to community and health services to ensure the most preventive approaches. Once officers arrive at their destination, they need to do a self-check similar to other professions at high risk for trauma and experiencing serious incidents. Similar to traditional policing, discretion and "clinical" judgement are necessary for positive outcomes.

\section{Step 1: West and East (De-Escalate and Disengage)}

The first step is de-escalating any situation, especially in calls with mental health or diversity factors. Most calls can be de-escalated. The multiple areas involved are briefly described in Table III (Williams et al., 2019). Some questions that police in the West area use include:

1. What is your name?

2. Identify yourself. "Hi my name is...." and "I want to help you"

3. How can I help you?

4. Where do you live?

5. When did you last eat?

6. When did you last sleep? For how long?

7. Tell me what is going on?

8. What kind of problems are you having? 


\section{$\underline{\text { No Disposition }}$}

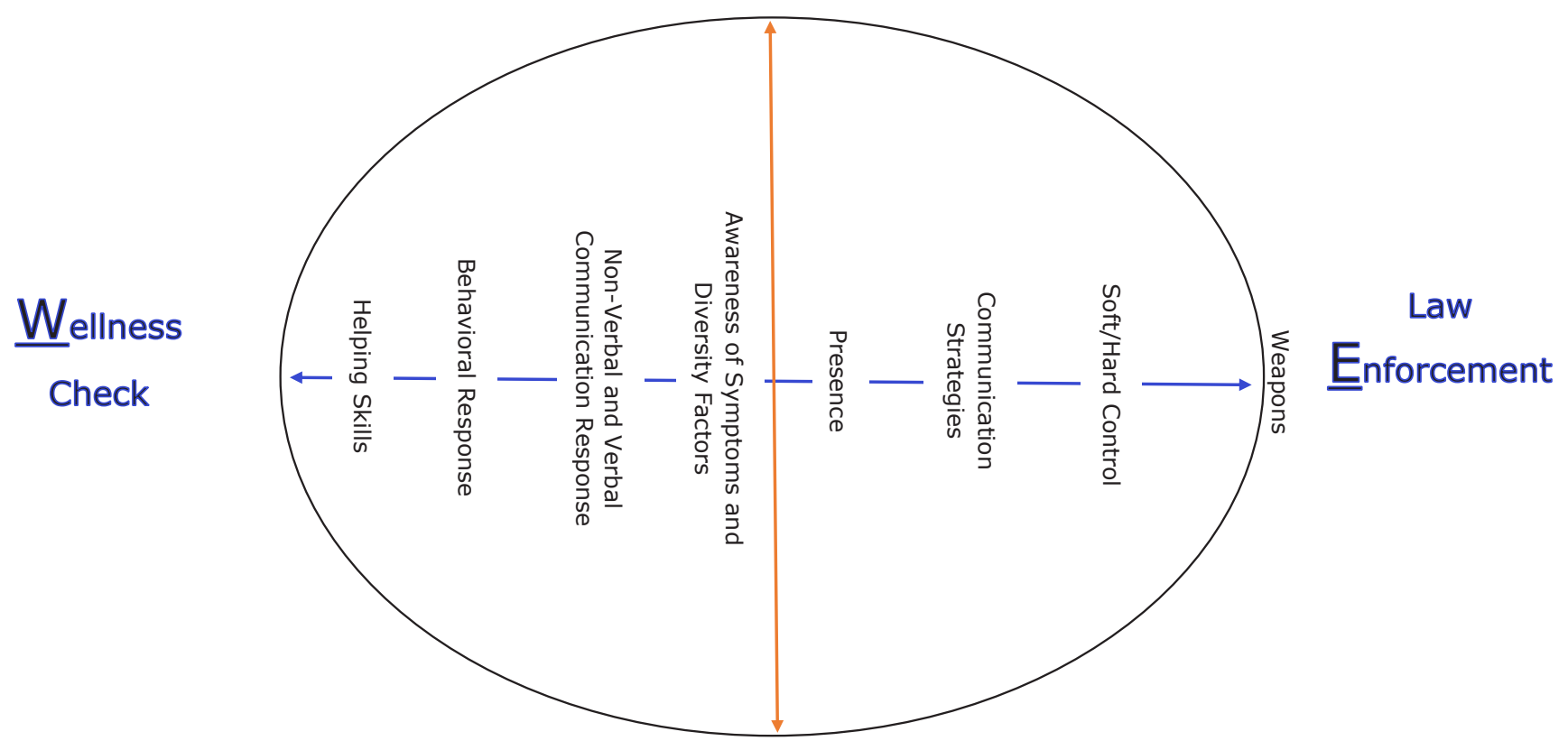

\section{Services in Community and Health Systems}

FIGURE 1 Compass Police Response (CPR) Model.

9. Do you take medications? What medications are you supposed to take? When was the last time you took your medication?

10. When was the last time you saw a doctor? What is your treatment for?

11. What types of fears do you have? What is causing those fears?

12. What are your plans? What are you going to do now?

13. Do you have any suicidal intents?

14. How is your mental health? Do you have any mental health concerns you want us to be aware of in order to assist you?

Always default to the West area, and return towards the West area if you enter the East. The East side of the map represents traditional tenets of police response from a law enforcement and safety perspective. When dealing with general mental health conditions or crises, the far East is not where your compass should be unless you are in the rare situation where law enforcement is required to provide immediate safety. If you enter the East, re-navigate to the West when appropriate. A key aspect symbolic of being a good driver and avoiding collisions is accurately appraising the true level of threat perception as you navigate a situation.

Weapons are placed outside the map as a means of last resort and it is not necessary to go out to that area unless you are absolutely left with no choice. If the person perceives you as a threat and they are suicidal, disengage and defer to the appropriate clinical experts. Always remain professional and follow officer safety tactics.
In this step, police need to also focus on diversity, although this paper does not provide an in-depth treatment of diversity. One element to consider is ideas that will break through current biases and barriers that exist in police culture, such as isolation and hyper-masculinity (Joseph Hayes, personal communication, July 16, 2020).

\section{Step 2: North and South (Disposition)}

Decide on an appropriate disposition that focuses on a preventive or rehabilitative approach that will enhance the ability or functioning of the individual to effectively resolve the issue. For example, the officer can simply provide support or comfort to the person, or if the person asks for help, the officer can connect the person with the appropriate services. The officer, if they choose, can provide their business contact information in case a person decides to seek assistance in the future. Each police organization or unit should lay out the dispositions available to the officers because the disposition component of the CPR model should be customized to the police organization and its relationships in the community. To appropriately decide on disposition options, it is imperative police units are knowledgeable about and connected to community and health resources (as well as other systems such as government and education services).

\section{Step 3: Arrival (Destination)}

Self-check of health and reflection. Did you experience any distress? Based on your experience, do you wish to undertake more learning about the issue encountered? If weapons were deployed, it is crucial that the officer partake in counselling 
TABLE III

Components of the West Area of the Compass Police Response (CPR) Model (see Williams, Jones, \& Reddon, 2019)

\section{Awareness of Symptoms and Diversity Factors}

Knowledge of mental health and mental health disorders including signs of crisis and symptoms of disorders. Empathetic awareness of current issues experienced by visible minorities, from developmental disabilities to ethnicities.

- Historical treatment of persons with mental health disorders

- History of policing with minoritized populations

- Issues of diverse populations

Knowledge of mental health disorders (anxiety, mood, psychosis, trauma, childhood, personality, substance use disorders, etc.)

\section{Non-Verbal Communication Response}

Use of body stance and posture

Understanding of facial expressions

Distance and personal space

Remaining calm and alert

Awareness that weapons can exacerbate the situation

Verbal Communication Response

Use of appropriate tone

Use of appropriate volume

Choice of words and use of simple words

Initiation of discussion without forcing discussion

Not ridiculing or using inflammatory language

Not speaking over the individual

Not giving orders rapidly, shouting, or arguing

Not lying about outcomes

Not expecting a rational discussion or engaging in a debate

\section{Behavioural Response}

\section{Getting person's attention}

Gathering all possible information from nearby bystanders and family

Being aware of the effects of equipment and presence

Removing distractions, upsetting influences, and disruptive persons

Providing reassurance that officer is there to assist the person and not cause them more problems

Not responding to criticism/verbal abuse, focusing on the objective of the person's safety

\section{Helping Skills}

Respect, Dignity, Care, Compassion, Courtesy, Empathy, Genuineness, Trust, Patience, Reasonable flexibility, Dependability, Non-judgement, Proper attitude, Social modelling, Avoiding hostility, Confidentiality, Privacy, Professionalism (minimize swearing, value judgements, be objective)

to debrief and assess trauma. In Canadian policing, $89 \%$ of time-loss claims were due to trauma injury or traumatic disorder (Cohen \& Garris, 2018).

\section{CONTEMPORARY SHORTCOMINGS OF THE USE OF FORCE FRAMEWORK AND WHY IT IS NO LONGER SUFFICIENT FOR COMPASSIONATE POLICING}

The National Use of Force Framework is a depiction of the various response methods used by police and "elements involved in the process by which a police officer assesses a situation and acts in a reasonable manner to ensure officer and public safety" (Canadian Association of Chiefs of Police, 2000). The current Use of Force Framework used in Canada has many limitations. The framework was created by 21 individuals who are predominantly White males in policing, so little insight into mental health and diversity was offered. We will highlight some significant aspects that render it outdated and ineffective in today's policing profession, and potentially compromise police practice.

First, a shortcoming of this framework is that it teaches officers to assume the worst case scenario because it predicates a need for constant, immediate safety. Policing is a dangerous profession, with most fatalities resulting from acts of violence or car accidents. However, the police officer fatality rate in Canada is 0.7 per 1,000, consisting of 45 fatalities from 2006 to 2015 based on an average of 67,395 officers (Cohen \& Garris, 2018). While police work does involve danger, the extreme responses of force used by some police officers in wellness calls are disproportionate to the risk involved. 
Second, the name itself implies the use of force. The first recommendation is therefore to rename the framework to Police Response Framework.

Third, the current framework provides no visual graphic to guide officers in the handling of persons experiencing mental health crises - there is no visual indication of deescalation and disengagement or returning to a safer point once the situation is controlled; de-escalation is therefore deemphasized compared with response escalation. For example, the communication section should visually include interpersonal and behavioural skills essential in police work. While each police agency is afforded robust additions to the Use of Force Framework in advancing de-escalation training, public and critic perception shows a police response where de-escalation is not highlighted or considered a priority. Figure 2 shows the revision of the Use of Force Framework to incorporate an appropriate response to mental health as suggested in sections of this manuscript. The current framework is reactive to others' behaviour and requires a focus on the officer's perception, techniques, and control (see Taylor (2020) for an in-depth discussion on officer presence and self-awareness). The Use of Force Framework needs to be more officer-internal focused than officer-external focused in addition to visually emphasizing de-escalation and responding to mental health crises.

Finally, subconsciously, the use of force framework depicts erroneous perceptions in escalation and proportions of engagement in response through a reactive black and white centre rather than one that allows the officer to evaluate their response. For example, the proportion of red to represent lethal response is approximately $16 \%$ to $20 \%$ of the circle. In reality, lethal response equates to $2 \%$ of police calls; as well, injury to officers is higher when any type of force is used, whether the person was compliant or resistant (Kiedrowski, et al., 2015). Approximately $50 \%$ to $80 \%$ of police calls are non-criminal, and a high proportion of calls consist of mental health and addictions (Mazowita \& Rotenberg 2019). As such, the progression from communication to soft

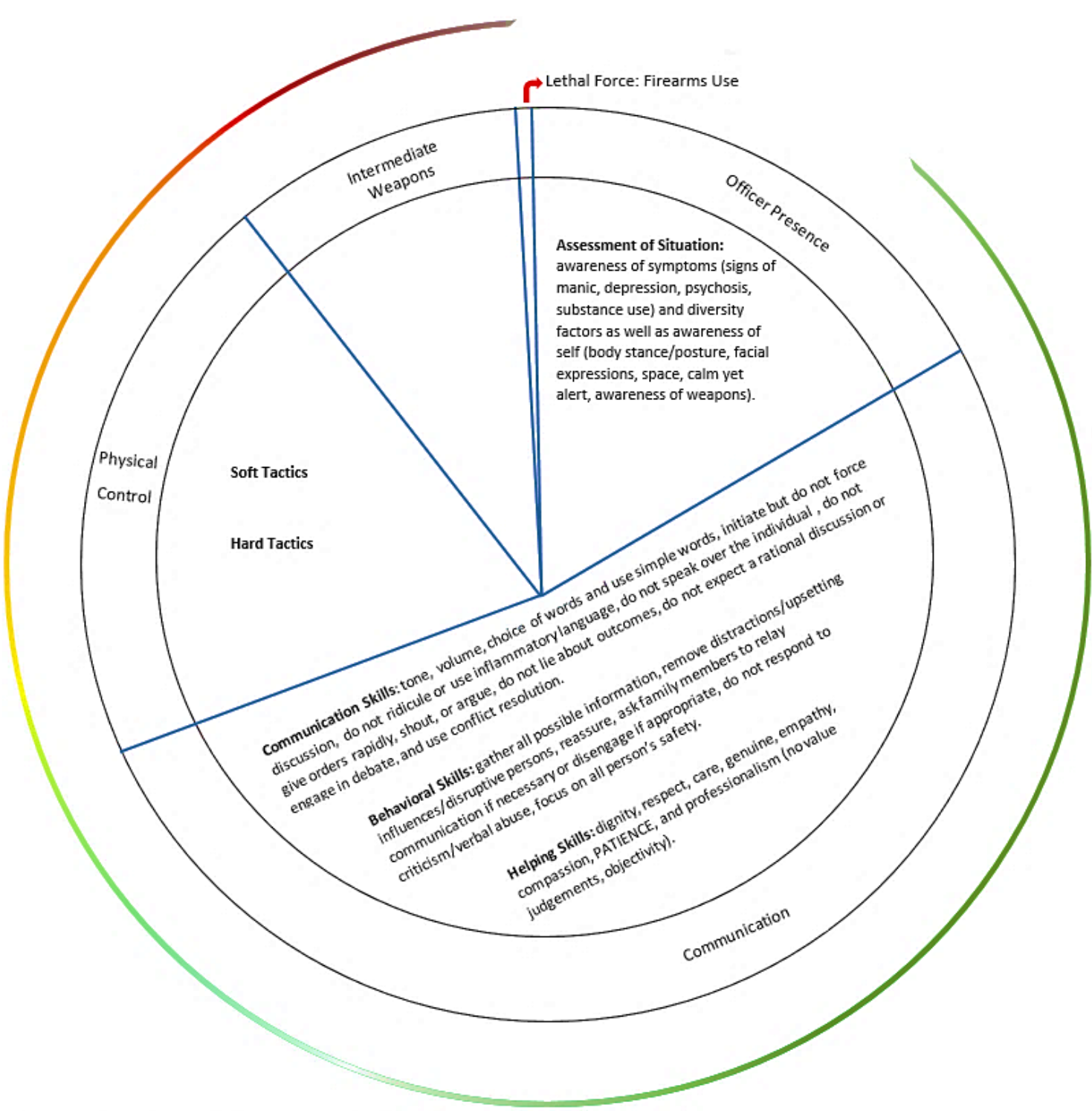

FIGURE 2 Revised national use of force framework. 
tactics is too immediate, sudden, and over-responsive. The yellow physical control must begin much further on from the time a call begins than what is depicted in the original Use of Force Framework.

\section{DISCUSSION}

An appropriate response to any police situation begins with professionalism and proper treatment of vulnerable groups, which means humanizing individuals by adopting the basic tenets of the helping profession-specifically that every person deserves respect, care, dignity, compassion, and empathy (Egan, 2013). These tenets promote a person-centred approach and need to be incorporated in the policing profession.

Too often, officers, much like other health and social professionals, become jaded and develop cognitive schemas that people who are "junkies" are different from "normal" people. However, from a mental health perspective, we learn that addiction is a disease embedded in a biological system, complemented by complex environmental and personal factors, such as trauma, grief, and social modelling.

Policing professionalism must address the treatment of high-risk groups, such as gangs and sex-trade workers, whose lives are often devalued. A simple reminder to all officers is that people in gangs or the sex trade are loved parents, siblings, and children. Persons living a high-risk lifestyle experience immense turmoil throughout their lives and often die at a younger age, which impacts their families and friends, who have to endure grief and heartache. The family and friends may despise society and police who demonstrate a lack of care, empathy, compassion, and justice for their loved one, and the impact can last generations.

Another aspect of police professionalism that needs to be addressed is the use of profanity. Profane language may be effective in an immediate situation, but it embodies aggression and coercion-a path police need to steer 180 degrees from in order to get to the "West" area. Police should be reminded that the health and social professions empathize and admire police officers in their ability to maintain calmness and composure in difficult situations.

Detasking police wellness checks into the community may offload law enforcement onto community/health professionals who are not adequately trained if a situation becomes potentially violent (this is a potential risk for some symptoms such as persecutory delusions and hallucinations). While it is questionable whether police have the capacity to deal with mental health challenges, before detasking to shift response to mental health from the police to community or health agencies, it is important to evaluate whether these agencies have the capacity and training to manage mental health crisis situations. It is fruitless to detask or defund police as a means of punishment. Instead, the policing profession needs support to develop further competency and become more collaborative with other professions because, mirroring the community itself, police work does not occur in silos.

On the other hand, we need to acknowledge that further education and training are necessary to adequately equip police for their work duties in addition to regular burnout and trauma assessments. Research has shown that officers who are reprimanded often tend to have lower education levels (Paoline \& Terrill, 2007). Paoline and Terrill recommend that a two-year police-focused diploma or a four-year degree be considered the minimal level of qualifications for police, respectively, to decrease use of verbal force and physical force. The quality, rigor and depth of interpersonal training can be aligned to other health and social professions by requiring a two- or four-year education program among newly recruited police officers as well as requiring mental health and diversity refreshers on an ongoing, regular basis.

Even with the existence of mental health teams and abundant mental health community and health services, police will always have calls that have an element of mental health. While communities can lead prevention activities, police will always be involved in mental health calls, some of which pose an immediate threat of violence, which is not typically encountered in other frontline professions. As such, the policing profession is positioned to address, and even lead, mental health crisis intervention and diversity competency in the future if current shortcomings are addressed.

\section{CONCLUSION}

The rare circumstances in which police have lacked compassion and professionalism have led to the current "war" on police brutality that all officers are now facing. The recent events surrounding George Floyd and wellness checks gone wrong in Canada have paved the way for police reform. Police will always deal with individuals who live with psychopathology, addictions, poverty, and cognitive deficits. As such, the amount of mental health and diversity training they receive needs to complement the time spent learning about law enforcement and police science. It is crucial for police to build their helping skills and build policing as a personcentred profession in order to gain respect and community trust and be effective in their roles in crime prevention and law enforcement. Most officers go into policing to help people. They need to remember that the most vulnerable people suffer the greatest impact when officers develop a jaded view. Due to the positive impact policing can have among underprivileged groups (Tyler \& Fagan 2008), policing is required in communities, but all officers must show a higher standard of professionalism and ethical treatment of vulnerable groups.

\section{CONFLICT OF INTEREST DISCLOSURES}

The authors declare that there are no conflicts of interest.

\section{AUTHOR AFFILIATIONS}

* MacEwan University, Edmonton, AB.

\section{REFERENCES}

Ariel, B., Farrar, W. A., \& Sutherland, A. (2015). The effect of police body-worn cameras on use of force and citizens' complaints against the police: A randomized controlled trial. Journal of Quantitative Criminology, 31(3), 509-535

Canadian Association of Chiefs of Police. (2000). A National use of force framework. Retrieved from: https://cacp.ca/policiesguidelines. htmle asst_id $=199$

Canadian Mental Health Association BC Division. (2005). Police and mental illness: Increased interactions. Retrieved from: https://cmha. bc.ca/wp-content/uploads/2016/07/policesheets_all.pdf

Cohen, I. M., \& Garis, L. (2018). Determinants of injury and death in Canadian police officers. Abbotsford: Centre for Criminal Justice Research. 
Donahue, J. J. (2020). Fight-flight-freeze system. Encyclopedia of personality and individual differences, 1590-1595.

Egan, G. (2013). The skilled helper: A problem-management and opportunity-development approach to helping. Cengage Learning.

Goldberg, V., White, C., \&Weisburd, D. (2019). Perspectives of people with mental health problems at hot spots: Attitudes and perceptions of safety, crime, and the police. Behavioral Sciences \& the Law, 37(6), 650-664.

Hall, C., Votova, K., Heyd, C., Walker, M., MacDonald, S., Eramian, D., \& Vilke, G. M. (2015). Restraint in police use of force events: examining sudden in-custody death for prone and not-prone positions. Journal of Forensic and Legal Medicine, 31, 29-35.

Kiedrowski, J. S., Melchers, R. F., Petrunik, M., \& Maxwell, C. (2015). A discussion of the collection and analysis of data on the use of force in encounters between the police and members of the public. Public Safety Canada

Laurance, J. (2003). Pure madness: How fear drives the mental health system. Psychology Press.

Lindon, G., \& Roe, S. (2017). Deaths in police custody: A review of the international evidence. London: Home Office.

Mazowita, B., \& Rotenberg, C. (2019). The Canadian police performance metrics framework: Standardized indicators for police services in Canada. Juristat: Canadian Centre for Justice Statistics, 1-13.

Mimiaga, M. J., Safren, S. A., Dvoryak, S., Reisner, S. L., Needle, R., \& Woody, G. (2010). "We fear the police, and the police fear us": Structural and individual barriers and facilitators to HIV medication adherence among injection drug users in Kiev, Ukraine. AIDS Care, 22(11), 1305-1313.

Nix, J., \& Wolfe, S. E. (2017). The impact of negative publicity on police self-legitimacy. Justice Quarterly, 34(1), 84-108.

Paoline III, E. A., \& Terrill, W. (2007). Police education, experience, and the use of force. Criminal Justice and Behavior, 34(2), 179-196.

Porges, S. W. (2009b). Stress and parasympathetic control. In L. R. Squire (Ed.), Encyclopedia of neuroscience (Vol. 9, pp. 463-469). Oxford: Academic Press

Porges, S. W. (2010). Stress and parasympathetic control. In L. R. Squire (Ed.), Encyclopedia of Neuroscience (Vol. 9, pp. 463-469). Academic Press.
Ross, D. L. (1998). Factors associated with excited delirium deaths in police custody. Modern Pathology, 11(11), 1127-1137.

Sweeney, A., Gillard, S., Wykes, T., \& Rose, D. (2015). The role of fear in mental health service users' experiences: A qualitative exploration. Social Psychiatry and Psychiatric Epidemiology, 50(7), 1079-1087.

State of Minnesota v. Derek Chauvin. File No. 27-CR-20-12646 (Minnesota District Court, Fourth Judicial District. June 2020). Retrieved from: https://web.archive.org/web/20200604085340/ http://mncourts.gov/mncourtsgov/media/High-Profile-Cases/27CR-20-12646/AmendedComplaint06032020.pdf

Smith Lee, J. R., \& Robinson, M. A. (2019). "That's my number one fear in life. It's the police": Examining young black men's exposures to trauma and loss resulting from police violence and police killings. Journal of Black Psychology, 45(3), 143-184.

Tankebe, J. (2014). Rightful authority: Exploring the structure of police self-legitimacy. Available at SSRN 2499717.

Taylor, N. E. (2020). Systemic or systematic: Officer presence and the eye of the beholder. Journal of Community Safety and Well-Being 5(3), 87-88.

Thompson, M., \& Kahn, K. B. (2016). Mental health, race, and police contact: Intersections of risk and trust in the police. Policing: An International Journal of Police Strategies \& Management, 39(4), 807-819.

Tyler, T. R., \& Fagan, J. (2008). Legitimacy and cooperation: Why do people help the police fight crime in their communities? Ohio State Journal of Criminal Law, 6, 231.

Vaughan, A. D., Zabkiewicz, D. M., \& Verdun-Jones, S. N. (2017). Incustody deaths of men related to mental illness and substance use: A cross-sectional analysis of administrative records in Ontario, Canada. Journal of Forensic and Legal Medicine, 48, 1-8.

Webster, V., Brough, P., \& Daly, K. (2016). Fight, flight or freeze: Common responses for follower coping with toxic leadership. Stress and Health, 32(4), 346-354.

Williams, U., Jones, D. J., \& Reddon, J. R. (2019). Police response to mental health in Canada. Canadian Scholars.

Wobeser, W. L., Datema, J., Bechard, B., \& Ford, P. (2002). Causes of death among people in custody in Ontario, 1990-1999. Canadian Medical Association Journal, 167(10), 1109-1113. 